Article

\title{
On Recent Results Concerning F-Contraction in Generalized Metric Spaces
}

\author{
Jelena Vujaković ${ }^{1, *}$, Slobodanka Mitrović ${ }^{2}$ and Mirjana Pavlović ${ }^{3, *}$ and Stojan Radenović 4 \\ 1 Department of Mathematics, Faculty of Sciences, University of Priština-Kosovska Mitrovica, \\ 38220 Kosovska Mitrovica, Serbia \\ 2 Faculty of Forestry, University of Belgrade, Kneza Višeslava 1, 11000 Beograd, Serbia; \\ slobodanka.mitrovic@sfb.bg.ac.rs \\ 3 Department of Mathematics and Informatics, Faculty of Sciences, University of Kragujevac, \\ Radoja Domanovića 12, 34000 Kragujevac, Serbia \\ 4 Faculty of Mechanical Engineering, University of Belgrade, Kraljice Marije 16, 11120 Beograd, Serbia; \\ radens@beotel.rs \\ * Correspondence: jelena.vujakovic@pr.ac.rs (J.V.); mpavlovic@kg.ac.rs (M.P.)
}

Received: 16 April 2020; Accepted: 7 May 2020; Published: 11 May 2020

\begin{abstract}
In this manuscript we discuss, consider, generalize, improve and unify several recent results for so-called $F$-contraction-type mappings in the framework of complete metric spaces. We also introduce $(\varphi, F)$-weak contraction and establish the corresponding fixed point result. Using our new approach for the proof that a Picard sequence is a Cauchy in metric space, our obtained results complement and enrich several methods in the existing literature. At the end we give one open question for F-contraction of Ćirić-type mapping.
\end{abstract}

Keywords: banach principle; $F$-contractive mapping; metric space; fixed point; $(\varphi, F)$-contraction

MSC: 47H10; 54H25

\section{Introduction}

Let $X$ be a nonempty abstract set and $T: X \rightarrow X$ a self-mapping of $X$. A solution of an equation $T(x)=x$ is called a fixed point of $T$. Theorems dealing with the existence and construction of a solution to an operator equations $T(x)=x$ are part of Fixed Point Theory. The Fixed Point Theory is one of the main areas of research in nonlinear analysis. Brouwer's and Banach's fixed point theorem are the two most important theorems of this Theory. Banach's fixed point theorem is an important tool in the metric theory of the fixed point. It solves:

- the problem on the existence of a unique solution to an equation,

- gives a practical method to obtain approximative solutions and

- gives an estimate of such solutions.

The applications of the Banach fixed point theorem and its generalization are very important in various disciplines of mathematics, statistics, engineering and economics.

Banach contraction mapping principle [1] is one of the most simple and in the same time the most important tests for existence and uniqueness of solution of problems arising in mathematics, and it has applications in engineering (for instance see [2,3]).

Let $(X, d)$ be a metric space and $T$ a mapping of $X$ into itself. A mapping $T$ is said to be a contraction mapping if and only if there exists a constant $\lambda, 0<\lambda<1$, such that for all $x, y \in X$,

$$
d(T x, T y) \leq \lambda d(x, y)
$$


A sequence $\left\{T^{n} x\right\}_{n=0}^{+\infty}$ where $T^{n} x=T\left(T^{n-1} x\right), T^{0} x=x, x \in X$, is called iterative sequence or orbit of $x$ by $T$.

Now we will formulate Banach contraction mapping principle for an arbitrary metric space, note that Banach formulated it for a complete normed space.

Theorem 1. (Banach [1], 1922) Let $(X, d)$ be a complete metric space and $T$ a contraction mapping of $X$ into itself. Then there exists a unique fixed point of $T$, say $\xi$, and $\lim _{n \rightarrow+\infty} T^{n} x=\xi$.

The extensive application of this principle has motivated many researchers to study possibility of its generalization. A great number of generalizations of this famous result have appeared in the literature. Basically there are two directions that can be taken. On the one hand, the usual contractive condition is weakened, while, on the other hand, the basic space is enriched by some generalization of the standard metric space ( $b$-metric space, partial metric space, $G$-metric space, $b$-metric-like space,..$)$. In 2012 D. Wardowski [4] introduced the so-called F-contraction.

Definition 1. Let $F:(0,+\infty) \rightarrow(-\infty,+\infty)$ be a mapping satisfying:

$\left(F_{1}\right) \quad F$ is strictly increasing, i.e., for all $\alpha, \beta \in(0,+\infty), \alpha<\beta$ implies $F(\alpha)<F(\beta)$;

$\left(F_{2}\right) \quad$ For each sequence $\left\{\alpha_{n}\right\}_{n \in \mathbb{N}} \subset(0,+\infty), \lim _{n \rightarrow+\infty} \alpha_{n}=0$ if and only if $\lim _{n \rightarrow+\infty} F\left(\alpha_{n}\right)=-\infty$;

$\left(F_{3}\right) \quad$ There exists $k \in(0,1)$ such that $\lim _{\alpha \rightarrow 0^{+}} \alpha^{k} F(\alpha)=0$.

A mapping $T: X \rightarrow X$ is a F-contraction on metric space $(X, d)$ if there exists $\tau>0$ such that for all $x, y \in X$,

$$
d(T x, T y)>0 \text { implies } \tau+F(d(T x, T y)) \leq F(d(x, y)) .
$$

Since then, several researchers (see [2-23]) are considered this concept of mapping. In their results, they used all three conditions of $F$-contraction. However, in this article we use only the first condition $\left(F_{1}\right)$. Our approach gives much shorter and nicer proofs of their results. It generalizes, complements, extends and improves several fixed point results in complete metric space.

Also in [4] Wardowski proved a genuine generalization of the Banach contraction principle [1] as follows:

Theorem 2. ([4]) Let $(X, d)$ be a complete metric space and $T: X \rightarrow X$ an F-contraction. Then $T$ has a unique fixed point $x^{*} \in X$ and for every $x \in X$ the sequence $\left\{T^{n} x\right\}_{n \in \mathbb{N}}$ converges to $x^{*}$.

Turinci in [21] observed that the condition $\left(F_{2}\right)$ can be relaxed to the form:

$\left(F_{2}^{\prime}\right) \lim _{t \rightarrow 0^{+}} F(t)=-\infty$.

For more details see ([18], Lemma 3.2 and Remark 3.1).

Further, D. Wardowski in [23] introduced a concept of $(\varphi, F)$-contraction (or nonlinear F-contraction):

Definition 2. A self-mapping $T$ on metric space $(X, d)$, for some functions $F:(0,+\infty) \rightarrow(-\infty,+\infty)$ and $\varphi:(0,+\infty) \rightarrow(0,+\infty)$, is said to be $(\varphi, F)$-contraction if the following condition holds:

$\left(H_{1}\right) \quad F$ satisfies $\left(F_{1}\right)$ and $\left(F_{2}^{\prime}\right)$;

$\left(H_{2}\right) \quad \liminf \operatorname{in}_{s \rightarrow t^{+}} \varphi(s)>0$ for all $t \geq 0$;

$\left(H_{3}\right) \quad \varphi(d(x, y))+F(d(T x, T y)) \leq F(d(x, y))$ for all $x, y \in X$ such that $T x \neq T y$.

Among other things, D. Wardowski in [23] proved and also genuinely generalized the main result from [4] with the following result: 
Theorem 3. ([23], Theorem 2.1) Let $(X, d)$ be a complete metric space and let $T: X \rightarrow X$ be a $(\varphi, F)$-contraction. Then $T$ has a unique fixed point.

We can prove the Wardowski's Theorem 3 for a $(\varphi, F)$-contraction on the easier way: using only the condition $\left(F_{1}\right)$ and the next two very well known Lemmas.

Lemma 1. ([24], Lemma 1; see also [25-27]) Let $\left\{x_{n}\right\}$ be a sequence in metric space $(X, d)$ such that $\lim _{n \rightarrow+\infty} d\left(x_{n}, x_{n+1}\right)=0$. If $\left\{x_{n}\right\}$ is not a Cauchy in $(X, d)$, then there exists $\varepsilon>0$ and two sequences $\left\{n_{k}\right\}$ and $\left\{m_{k}\right\}$ of positive integers such that $n_{k}>m_{k}>k$, and the sequences:

$$
d\left(x_{n_{k}}, x_{m_{k}}\right), d\left(x_{n_{k}+1}, x_{m_{k}}\right), d\left(x_{n_{k}}, x_{m_{k}-1}\right), d\left(x_{n_{k}+1}, x_{m_{k}-1}\right), d\left(x_{n_{k}+1}, x_{m_{k}+1}\right), \ldots
$$

tend to $\varepsilon^{+}$, as $k \rightarrow+\infty$.

Lemma 2. Let $\left\{x_{n+1}\right\}_{n \in \mathbb{N} \cup\{0\}}=\left\{T x_{n}\right\}_{n \in \mathbb{N} \cup\{0\}}=\left\{T^{n} x_{0}\right\}_{n \in \mathbb{N} \cup\{0\}}, T^{0} x_{0}=x_{0}$ be a Picard sequence in metric space $(X, d)$ inducing by mapping $T: X \rightarrow X$ and initial point $x_{0} \in X$. If $d\left(x_{n}, x_{n+1}\right)<d\left(x_{n-1}, x_{n}\right)$ for all $n \in \mathbb{N}$ then $x_{n} \neq x_{m}$ whenever $n \neq m$.

Proof. Let $x_{n}=x_{m}$ for some $n, m \in \mathbb{N}$ with $n<m$. Then $x_{n+1}=T x_{n}=T x_{m}=x_{m+1}$. Further, we get

$$
d\left(x_{n}, x_{n+1}\right)=d\left(x_{m}, x_{m+1}\right)<d\left(x_{m-1}, x_{m}\right)<d\left(x_{m-2}, x_{m-1}\right)<\ldots<d\left(x_{n}, x_{n+1}\right),
$$

which is a contradiction.

\section{Results}

In the following we present our first new result. We assumed that the function $F:(0,+\infty) \rightarrow$ $(-\infty,+\infty)$ satisfies only condition $\left(F_{1}\right)$ while the function $\varphi:(0,+\infty) \rightarrow(0,+\infty)$ has a property $\left(H_{2}\right)$.

Theorem 4. Let $(X, d)$ be a complete metric space and let $T: X \rightarrow X$ be a $(\varphi, F)$-contraction satisfying

$$
\varphi(d(x, y))+F(d(T x, T y)) \leq F(d(x, y))
$$

for all $x, y \in X$ with $T x \neq T y$. Then $T$ has a unique fixed point.

Proof. First of all, condition $\left(F_{1}\right)$ implies that there exists both $\lim _{x \rightarrow y^{-}} F(x)=F(y-0)$ and $\lim _{x \rightarrow y^{+}} F(x)=F(y+0)$ for all $y \in(0,+\infty)$. This fact is well known from real mathematical analysis and

$$
F(y-0) \leq F(y) \leq F(y+0),
$$

holds true for each $y \in(0,+\infty)$. Further, from the condition of $(\varphi, F)$-contraction and the fact that $\varphi:(0,+\infty) \rightarrow(0,+\infty)$, follows that $T$ is contractive $(x \neq y$ implies $d(T x, T y)<d(x, y))$. This means that the mapping $T$ is continuous. Also, $(\varphi, F)$-contraction gives the uniqueness of the fixed point if it exists. In order to show that $T$ has a fixed point, let $x_{0}$ be arbitrary point in $X$. Now, we define a sequence $\left\{x_{n}\right\}_{n \in \mathbb{N} \cup\{0\}}$, with $x_{n+1}=T x_{n}$. If $x_{k}=x_{k+1}$ for some $k \in \mathbb{N} \cup\{0\}$ then $x_{k}$ is a unique fixed point and the proof of Theorem 4 is completed. Therefore, suppose now that $x_{n} \neq x_{n+1}$ for every $n \in \mathbb{N} \cup\{0\}$. By $(\varphi, F)$-contraction it follows that

$$
F\left(d\left(x_{n}, x_{n+1}\right)\right)<\varphi\left(d\left(x_{n-1}, x_{n}\right)\right)+F\left(d\left(x_{n}, x_{n+1}\right)\right) \leq F\left(d\left(x_{n-1}, x_{n}\right)\right),
$$


for all $n \in \mathbb{N}$, that is, according to $\left(F_{1}\right)$ we have $d\left(x_{n}, x_{n+1}\right)<d\left(x_{n-1}, x_{n}\right)$ for all $n \in \mathbb{N}$. This further means that $d\left(x_{n}, x_{n+1}\right) \rightarrow d^{*} \geq 0$ as $n \rightarrow+\infty$ as well as $d\left(x_{n}, x_{n+1}\right)>d^{*}$ for all $n \in \mathbb{N} \cup\{0\}$. Suppose that $d^{*}>0$. Based on $\left(H_{2}\right)$, there exists $\tau>0$ and some $n_{1} \in \mathbb{N}$ such that for all $n \geq n_{1}$ we have

$$
\tau+F\left(d\left(x_{n}, x_{n+1}\right)\right) \leq \varphi\left(d\left(x_{n-1}, x_{n}\right)\right)+F\left(d\left(x_{n}, x_{n+1}\right)\right) \leq F\left(d\left(x_{n-1}, x_{n}\right)\right),
$$

that is,

$$
\tau+F\left(d\left(x_{n}, x_{n+1}\right)\right) \leq F\left(d\left(x_{n-1}, x_{n}\right)\right),
$$

for all $n \geq n_{1}$. Hence we obtain

$$
\tau+F\left(d^{*}+0\right) \leq F\left(d^{*}+0\right),
$$

which is a contradiction. Therefore, $\lim _{n \rightarrow+\infty} d\left(x_{n}, x_{n+1}\right)=0$. Now, we will prove that $\left\{x_{n}\right\}_{n \in \mathbb{N} \cup\{0\}}$ is a Cauchy sequence by assuming the opposite. If we take $x=x_{n_{k}}$ and $y=x_{m_{k}}$ in $(\varphi, F)$-contraction (it is possible by Lemma 2), we get

$$
\varphi\left(d\left(x_{n_{k}}, x_{m_{k}}\right)\right)+F\left(d\left(x_{n_{k}+1}, x_{m_{k}+1}\right)\right) \leq F\left(d\left(x_{n_{k}}, x_{m_{k}}\right)\right) .
$$

Since, by Lemma 1, both $d\left(x_{n_{k}+1}, x_{m_{k}+1}\right)$ and $d\left(x_{n_{k}}, x_{m_{k}}\right)$ tend to $\varepsilon^{+}$as $k \rightarrow+\infty$, we obtain

$$
\begin{gathered}
\lim _{d\left(x_{n_{k}}, x_{m_{k}}\right) \rightarrow \varepsilon^{+}}^{\inf } \varphi\left(d\left(x_{n_{k}}, x_{m_{k}}\right)\right)+\lim \underset{d\left(x_{n_{k}+1}, x_{m_{k}+1}\right) \rightarrow \varepsilon^{+}}{\inf } F\left(d\left(x_{n_{k}+1}, x_{m_{k}+1}\right)\right) \\
\leq \lim \inf _{d\left(x_{n_{k}}, x_{m_{k}}\right) \rightarrow \varepsilon^{+}} F\left(d\left(x_{n_{k}}, x_{m_{k}}\right)\right),
\end{gathered}
$$

i.e.,

$$
\lim \inf _{d\left(x_{n_{k}}, x_{m_{k}}\right) \rightarrow \varepsilon^{+}} \varphi\left(d\left(x_{n_{k}}, x_{m_{k}}\right)\right)+F\left(\varepsilon^{+}+0\right) \leq F\left(\varepsilon^{+}+0\right) .
$$

This is in contradiction to $\liminf _{d\left(x_{n_{k}}, x_{m_{k}}\right) \rightarrow \varepsilon^{+}} \varphi\left(d\left(x_{n_{k}}, x_{m_{k}}\right)\right)>0$. We conclude that $\left\{x_{n}\right\}_{n \in \mathbb{N} \cup\{0\}}$ is a Cauchy sequence. Since $(X, d)$ is a complete metric space, it converges to some point $x^{*} \in X$. On the other hand, the continuity of the mapping $T$ implies $T x^{*}=x^{*}$, i.e. $x^{*}$ is a unique fixed point of $T$ and we have proved the theorem.

Corollary 1. Taking $\varphi(t)=\tau>0$ in Theorem 4, we obtain the Theorem 2 from [4].

Remark 1. It is worth to mention that our method in the proof of Theorem 4 improve, generalize, complement, unify and enrich the corresponding ones from [23].

In the sequel we consider the article of Wardowski-Dung [22]. In it, the authors introduced the notion of $F$-weak contraction as follows:

Definition 3. Let $(X, d)$ be a metric space. A mapping $T: X \rightarrow X$ is said to be a F-weak contraction on $(X, d)$ if there exists $F:(0,+\infty) \rightarrow(-\infty,+\infty)$ satisfying $\left(F_{1}\right),\left(F_{2}\right)$ and $\left(F_{3}\right)$ and $\tau>0$ such that, for all $x, y \in X$ with $d(T x, T y)>0$, the following holds:

$$
\tau+F(d(T x, T y)) \leq F(M(x, y))
$$

where $M=\max \left\{d(x, y), d(x, T x), d(y, T y), \frac{d(x, T y)+d(y, T x)}{2}\right\}$.

Further, the authors in the same article proved the following result, which generalized results from [4]. 
Theorem 5. Let $(X, d)$ be a complete metric space and $T: X \rightarrow X$ be a F-weak contraction. If $T$ or $F$ is continuous, then $T$ has a unique fixed point $x^{*} \in X$ and for all $x \in X$, the sequence $\left\{T^{n} x\right\}_{n \in \mathbb{N}}$ converges to $x^{*}$.

Inspired with contractive Definition 3 we introduce the following notion:

Definition 4. Let $(X, d)$ be a metric space. A mapping $T: X \rightarrow X$ is said to be a $(\varphi, F)-$ weak contraction on $(X, d)$ if there exists $F:(0,+\infty) \rightarrow(-\infty,+\infty)$ and $\varphi:(0,+\infty) \rightarrow(0,+\infty)$ satisfying $\left(F_{1}\right)$ and $\left(\mathrm{H}_{2}\right)$ respectively such that for all $x, y \in X$ with $T x \neq T y$ :

$$
\varphi(d(x, y))+F(d(T x, T y)) \leq F(M(x, y))
$$

where $M(x, y)=\max \left\{d(x, y), d(x, T x), d(y, T y), \frac{d(x, T y)+d(y, T x)}{2}\right\}$.

Our following result generalizes ones from [22] in several directions:

Theorem 6. Let $(X, d)$ be a complete metric space and let $T: X \rightarrow X$ be $a(\varphi, F)$-weak contraction. If $T$ or $F$ is continuous, then

(1) Thas a unique fixed point $x^{*} \in X$.

(2) For all $x \in X$, the sequence $\left\{T^{n} x\right\}_{n \in \mathbb{N}}$ converges to $x^{*}$.

Proof. Since $T x \neq T y$ we have that both hand of (10) are well defined. Further, (10) give us that the uniqueness of the fixed point if it exists. In order to prove that $(\varphi, F)$-weak contraction $T$ has a fixed point, assume that $x_{0}$ is an arbitrary point in $X$. Now, we define a sequence $\left\{x_{n}\right\}_{n \in \mathbb{N} \cup\{0\}}$ with $x_{n+1}=T x_{n}$. If $x_{k}=x_{k+1}$, for some $k \in \mathbb{N} \cup\{0\}$, then $x_{k}$ is a unique fixed point and the proof of Theorem is finished. Therefore, suppose now that $x_{n} \neq x_{n+1}$ for all $n \in \mathbb{N} \cup\{0\}$. Then the condition (10) implies that for all $n \in \mathbb{N}$

$$
F\left(d\left(x_{n}, x_{n+1}\right)\right)<\varphi\left(d\left(x_{n-1}, x_{n}\right)\right)+F\left(d\left(x_{n}, x_{n+1}\right)\right) \leq F\left(M\left(x_{n-1}, x_{n}\right)\right)
$$

where

$$
M\left(x_{n-1}, x_{n}\right)=\max \left\{d\left(x_{n-1}, x_{n}\right), d\left(x_{n-1}, x_{n}\right), d\left(x_{n}, x_{n+1}\right), \frac{d\left(x_{n-1}, x_{n+1}\right)+0}{2}\right\}
$$

that is,

$$
\begin{aligned}
M\left(x_{n-1}, x_{n}\right) & =\max \left\{d\left(x_{n-1}, x_{n}\right), d\left(x_{n}, x_{n+1}\right), \frac{d\left(x_{n-1}, x_{n+1}\right)}{2}\right\} \\
\leq \max & \left\{d\left(x_{n-1}, x_{n}\right), d\left(x_{n}, x_{n+1}\right), \frac{d\left(x_{n-1}, x_{n}\right)+d\left(x_{n}, x_{n+1}\right)}{2}\right\} \\
& \leq \max \left\{d\left(x_{n-1}, x_{n}\right), d\left(x_{n}, x_{n+1}\right)\right\} .
\end{aligned}
$$

Finally, we obtain

$$
\begin{gathered}
F\left(d\left(x_{n}, x_{n+1}\right)\right)<\varphi\left(d\left(x_{n-1}, x_{n}\right)\right)+F\left(d\left(x_{n}, x_{n+1}\right)\right) \\
\leq F\left(\max \left\{d\left(x_{n-1}, x_{n}\right), d\left(x_{n}, x_{n+1}\right)\right\}\right) .
\end{gathered}
$$

It is clear that $\max \left\{d\left(x_{n-1}, x_{n}\right), d\left(x_{n}, x_{n+1}\right)\right\}=d\left(x_{n-1}, x_{n}\right)$. Otherwise we get $d\left(x_{n}, x_{n+1}\right)<$ $d\left(x_{n}, x_{n+1}\right)$, which is a contradiction. Hence, we get

$$
F\left(d\left(x_{n}, x_{n+1}\right)\right)<\varphi\left(d\left(x_{n-1}, x_{n}\right)\right)+F\left(d\left(x_{n}, x_{n+1}\right)\right) \leq F\left(d\left(x_{n-1}, x_{n}\right)\right)
$$


for all $n \in \mathbb{N}$. Based on $\left(F_{1}\right)$, the relation (12) further means: $d\left(x_{n}, x_{n+1}\right)<d\left(x_{n-1}, x_{n}\right)$, i.e., $\lim _{n \rightarrow+\infty} d\left(x_{n}, x_{n+1}\right)=d^{*} \geq 0$. Then by $\left(H_{2}\right)$ it follows that there exists $\tau>0$ and $n_{1} \in \mathbb{N}$ such that for all $n \geq n_{1}$

$$
\tau+F\left(d\left(x_{n}, x_{n+1}\right)\right) \leq \varphi\left(d\left(x_{n-1}, x_{n}\right)\right)+F\left(d\left(x_{n}, x_{n+1}\right)\right) \leq F\left(d\left(x_{n-1}, x_{n}\right)\right),
$$

i.e.,

$$
\tau+F\left(d\left(x_{n}, x_{n+1}\right)\right) \leq F\left(d\left(x_{n-1}, x_{n}\right)\right) .
$$

From the last it follows that

$$
\tau+F\left(d^{+}+0\right) \leq F\left(d^{+}+0\right)
$$

which is a contradiction. Hence, $\lim _{n \rightarrow+\infty} d\left(x_{n}, x_{n+1}\right)=0$. Now, we show that $\left\{x_{n}\right\}_{n \in \mathbb{N} \cup\{0\}}$ is a Cauchy sequence by supposing contrary. Putting $x=x_{n_{k}}$ and $y=x_{m_{k}}$ in (10) (it is possible by Lemma 2) we get

$$
\varphi\left(d\left(x_{n_{k}}, x_{m_{k}}\right)\right)+F\left(d\left(x_{n_{k}+1}, x_{m_{k}+1}\right)\right) \leq F\left(M_{k}\right)
$$

where

$$
M_{k}=\max \left\{d\left(x_{n_{k}}, x_{m_{k}}\right), d\left(x_{n_{k}}, x_{n_{k}+1}\right), d\left(x_{m_{k}}, x_{m_{k}+1}\right), \frac{d\left(x_{n_{k}+1}, x_{m_{k}}\right)+d\left(x_{n_{k}}, x_{m_{k}+1}\right)}{2}\right\} .
$$

Since, according to Lemma 1, all three $d\left(x_{n_{k}+1}, x_{m_{k}+1}\right), d\left(x_{n_{k}}, x_{m_{k}}\right)$ and $M_{k}$ tends to $\varepsilon^{+}$as $k \rightarrow$ $+\infty$, we obtain that

$$
\begin{gathered}
\lim \inf _{d\left(x_{n_{k}}, x_{m_{k}}\right) \rightarrow \mathcal{\varepsilon}^{+}} \varphi\left(d\left(x_{n_{k}}, x_{m_{k}}\right)\right)+\lim _{d\left(x_{n_{k}+1}, x_{m_{k}+1}\right) \rightarrow \varepsilon^{+}} F\left(d\left(x_{n_{k}+1}, x_{m_{k}+1}\right)\right) \\
\leq \lim \inf _{M_{k} \rightarrow \varepsilon^{+}} F\left(M_{k}\right)
\end{gathered}
$$

i.e.,

$$
\lim _{d\left(x_{n_{k}}, x_{m_{k}}\right) \rightarrow \varepsilon^{+}} \varphi\left(d\left(x_{n_{k}}, x_{m_{k}}\right)\right)+F\left(\varepsilon^{+}+0\right) \leq F\left(\varepsilon^{+}+0\right) .
$$

It is a contradiction with $\liminf _{d\left(x_{n_{k}}, x_{m_{k}}\right) \rightarrow \varepsilon^{+}} \varphi\left(d\left(x_{n_{k}}, x_{m_{k}}\right)\right)>0$, and we proved that $\left\{x_{n}\right\}_{n \in \mathbb{N} \cup\{0\}}$ is a Cauchy sequence in $X$. Since $(X, d)$ is complete, there exists $x^{*} \in X$ such that $\lim _{n \rightarrow+\infty} x_{n}=x^{*}$. We shall prove that $x^{*}$ is a fixed point of $T$ by observing two possible cases.

(I) Assume first that $T$ is continuous. We have

$$
\begin{aligned}
d\left(x^{*}, T x^{*}\right) & =d\left(\lim _{n \rightarrow+\infty} x_{n}, T\left(\lim _{n \rightarrow+\infty} x_{n}\right)\right)=d\left(\lim _{n \rightarrow+\infty} x_{n}, \lim _{n \rightarrow+\infty} T x_{n}\right) \\
& =d\left(\lim _{n \rightarrow+\infty} x_{n}, \lim _{n \rightarrow+\infty} x_{n+1}\right)=d\left(x^{*}, x^{*}\right)=0,
\end{aligned}
$$

that is, $x^{*}$ is a fixed point of $T$.

(II) Suppose now that $F$ is continuous and let $d\left(x^{*}, T x^{*}\right)>0$. Since, $x_{n} \neq x_{m}$, whenever $n \neq m$ (according to Lemma 2), then there exists $N \in \mathbb{N}$ such that $x^{*}, T x^{*} \notin\left\{x_{n}: n>N\right\}$. Hence and according to (10) we get

$$
\varphi\left(d\left(x_{n}, x^{*}\right)\right)+F\left(d\left(T x_{n}, T x^{*}\right)\right) \leq F\left(M\left(x_{n}, x^{*}\right)\right)
$$


where

$$
\begin{gathered}
M\left(x_{n}, x^{*}\right)=\max \left\{d\left(x_{n}, x^{*}\right), d\left(x_{n}, x_{n+1}\right), d\left(x^{*}, T x^{*}\right), \frac{d\left(x_{n}, T x^{*}\right)+d\left(x_{n+1}, x^{*}\right)}{2}\right\} \\
\leq \max \left\{d\left(x_{n}, x^{*}\right), d\left(x_{n}, x_{n+1}\right), d\left(x^{*}, T x^{*}\right), \frac{d\left(x_{n}, x^{*}\right)+d\left(x^{*}, T x^{*}\right)+d\left(x_{n+1}, x^{*}\right)}{2}\right\} \\
\rightarrow d\left(x^{*}, T x^{*}\right) \text { as } n \rightarrow+\infty .
\end{gathered}
$$

Since, $F\left(d\left(T x_{n}, T x^{*}\right)\right)=F\left(d\left(x_{n+1}, T x^{*}\right)\right)$ and $F\left(M\left(x_{n}, x^{*}\right)\right)$ tend to $F\left(d\left(x^{*}, T x^{*}\right)\right)$ as $n \rightarrow+\infty$, we obtain that

$$
\lim \inf _{d\left(x_{n}, x^{*}\right) \rightarrow 0^{+}} \varphi\left(d\left(x_{n}, x^{*}\right)\right)+F\left(d\left(x^{*}, T x^{*}\right)\right) \leq F\left(d\left(x^{*}, T x^{*}\right)\right)
$$

or

$$
\lim \inf _{d\left(x_{n}, x^{*}\right) \rightarrow 0^{+}} \varphi\left(d\left(x_{n}, x^{*}\right)\right) \leq 0,
$$

which is a contradiction. Thus, assumption $d\left(x^{*}, T x^{*}\right)>0$ is wrong, i.e. $x^{*}$ is a fixed point of $T$. The theorem is proved.

Consetino and Vetro [9] defined notion of F-contraction of Hardy-Rogers-type and generalized the main result of Wardowski [4].

Definition 5. Let $(X, d)$ be a metric space. A mapping $T: X \rightarrow X$ is called a F-contraction of Hardy-Rogers-type if there exists $\tau>0$ and $F:(0,+\infty) \rightarrow(-\infty,+\infty)$ satisfying $\left(F_{1}\right),\left(F_{2}\right)$ and $\left(F_{3}\right)$ such that

$$
\begin{gathered}
\tau+F(d(T x, T y)) \\
\leq F(\alpha \cdot d(x, y)+\beta \cdot d(x, T x)+\gamma \cdot d(y, T y)+\delta \cdot d(x, T y)+L \cdot d(y, T x))
\end{gathered}
$$

holds for any $x, y, \in X$ with $d(T x, T y)>0$, where $\alpha, \beta, \gamma, \delta$, L are non-negative numbers, $\gamma \neq 1$ and $\alpha+\beta+$ $\gamma+2 \delta=1$.

Theorem 7. Let $(X, d)$ be a complete metric space and let $T$ be a self-mapping on $X$. Assume that $T$ is a F-contraction of Hardy-Rogers-type, where $\gamma \neq 1$. Then $T$ has a fixed point. Moreover, if $\alpha+\delta+L \leq 1$, then the fixed point of $T$ is unique.

Very recently, Popescu and Stan introduced partial generalization of Wardowski's and Cosentino's and Vetro's resullts. They formulated and proved the following:

Theorem 8. ([17], Theorem 5) Let $T$ be a self-mapping of a complete metric space $(X, d)$ into itself. Suppose there exists $\tau>0$ such that for all $x, y \in X, d(T x, T y)>0$ implies

$$
\begin{gathered}
\tau+F(d(T x, T y)) \\
\leq F(\alpha \cdot d(x, y)+\beta \cdot d(x, T x)+\gamma \cdot d(y, T y)+\delta \cdot d(x, T y)+L \cdot d(y, T x)),
\end{gathered}
$$

where $F:(0,+\infty) \rightarrow(-\infty,+\infty)$ is an increasing mapping, $\alpha, \beta, \gamma, \delta, L$ are non-negative numbers, $\delta<{ }_{1} 2, \gamma<1, \alpha+\beta+\gamma+2 \delta=1,0<\alpha+\delta+L \leq 1$. Then $T$ has a unique fixed point $x^{*} \in X$ and for every $x \in X$ the sequence $\left\{T^{n} x\right\}_{n \in \mathbb{N}}$ converges to $x^{*}$.

Now we introduce notion of $(\varphi, F)$-weak contraction of Hardy-Rogers-type and using it we will generalize the result of Popescu and Stan. 
Definition 6. Let $(X, d)$ be a metric space. A mapping $T: X \rightarrow X$ is called a $(\varphi, F)$-weak contraction of Hardy-Rogers-type on $(X, d)$ if there exists $F:(0,+\infty) \rightarrow(-\infty,+\infty)$ and $\varphi:(0,+\infty) \rightarrow(0,+\infty)$ satisfying $\left(F_{1}\right)$ and $\left(H_{2}\right)$ respectively, such that for all $x, y \in X$ with $T x \neq T y$ :

$$
\begin{gathered}
\varphi(d(x, y))+F(d(T x, T y)) \\
\leq F(\alpha \cdot d(x, y)+\beta \cdot d(x, T x)+\gamma \cdot d(y, T y)+\delta \cdot d(x, T y)+L \cdot d(y, T x))
\end{gathered}
$$

where $\alpha, \beta, \gamma, \delta, L$ are non-negative numbers, $\gamma<1, \delta<\frac{1}{2}, \alpha+\beta+\gamma+2 \delta=1$.

Theorem 9. Let $(X, d)$ be a complete metric space and let $T: X \rightarrow X$ be a $(\varphi, F)$-weak contraction of Hardy-Rogers-type. If $T$ or $F$ is continuous, then

(1) Thas a unique fixed point $x^{*} \in X$, when $0<\alpha+\delta+L \leq 1$;

(2) For all $x \in X$, the sequence $\left\{T^{n} x\right\}_{n \in \mathbb{N}}$ converges to $x^{*}$.

Proof. The proof is similar like the ones from [17], i.e., our Theorem 6.

Corollary 2. As a consequence of Theorem 9, taking $\alpha=1$ and $\beta=\gamma=\delta=L=0$, we obtain our Theorem 4 and at the same time Wardowski's result from [23].

In 2014, Hussain and Salimi [12] proved several new and interesting results from the framework of F-contraction type mappings. Namely, they defined the following:

Definition 7. ([12], Definition 1.2) Let $T$ be a self-mapping on nonempty set $X$ and $\alpha, \eta: X \times X \rightarrow[0,+\infty)$ be two functions. The mapping $T$ is an $\alpha$-admissible mapping with respect to $\eta$ if

$$
x, y \in X, \alpha(x, y) \geq \eta(x, y) \text { implies } \alpha(T x, T y) \geq \eta(T x, T y) \text {. }
$$

Definition 8. ([12], Definition 1.3) Let $(X, d)$ be a metric space. Let $\alpha, \eta: X \times X \rightarrow[0,+\infty)$ and $T: X \rightarrow X$ be functions. Then $T$ is an $\alpha$ - $\eta$-continuous mapping on $(X, d)$, if, for given $x \in X$ and sequence $\left\{x_{n}\right\}$ with

$$
x_{n} \rightarrow x \text { as } n \rightarrow+\infty, \alpha\left(x_{n}, x_{n+1}\right) \geq \eta\left(x_{n}, x_{n+1}\right) \text { for all } n \in \mathbb{N} \text { implies } T x_{n} \rightarrow T x
$$

Example 1. ([12]) Let $X=[0,+\infty)$ and $d(x, y)=|x-y|$ be a metric on $X$. Assume, $T: X \rightarrow X$ and $\alpha, \eta: X \times X \rightarrow[0,+\infty)$ be defined by

$$
T x=\left\{\begin{array}{l}
x^{5}, \text { if } x \in[0,1] \\
\sin \pi x+2, \text { if } x \in(1,+\infty)
\end{array}, \alpha(x, y)=\left\{\begin{array}{l}
x^{2}+y^{2}+1, \text { if } x, y \in[0,1] \\
0, \text { otherwise }
\end{array}\right.\right.
$$

and $\eta(x, y)=x^{2}$. Clearly, $T$ is not continuous, but $T$ is $\alpha-\eta$-continuous on $(X, d)$.

Let $\triangle_{G}$ denotes the set of all continuous functions $G:[0,+\infty)^{4} \rightarrow[0,+\infty)$ satisfying:

(G) for all $t_{1}, t_{2}, t_{3}, t_{4} \in[0,+\infty)$ with $t_{1} \cdot t_{2} \cdot t_{3} \cdot t_{4}=0$ there exists $\tau>0$ such that $G\left(t_{1}, t_{2}, t_{3}, t_{4}\right)=\tau$.

Example 2. ([12]) If $G\left(t_{1}, t_{2}, t_{3}, t_{4}\right)=L \min \left\{t_{1}, t_{2}, t_{3}, t_{4}\right\}+\tau$ where $L \in[0,+\infty)$ and $\tau>0$, then $G \in \triangle_{G}$.

Example 3. ([12]) If $G\left(t_{1}, t_{2}, t_{3}, t_{4}\right)=\tau e^{L \min \left\{t_{1}, t_{2}, t_{3}, t_{4}\right\}}$ where $L \in[0,+\infty)$ and $\tau>0$, then $G \in \triangle_{G}$.

Example 4. ([12]) If $G\left(t_{1}, t_{2}, t_{3}, t_{4}\right)=L \ln \left(\min \left\{t_{1}, t_{2}, t_{3}, t_{4}\right\}+1\right)+\tau$ where $L \in[0,+\infty)$ and $\tau>0$, then $G \in \triangle_{G}$. 
Further, Hussain and Salimi defined new type of $F$-contractive mapping and proved the next new result:

Definition 9. ([12]) Let $(X, d)$ be a metric space and $T$ be a self-mapping on $X$. Also suppose that $\alpha, \eta$ : $X \times X \rightarrow[0,+\infty)$ be two functions. The mapping $T$ is said to be an $\alpha-\eta$-GF-contraction if for $x, y \in X$ with $\eta(x, T x) \leq \alpha(x, y)$ and $d(T x, T y)>0$ holds

$$
G(d(x, T x), d(y, T y), d(x, T y), d(y, T x))+F(d(T x, T y)) \leq F(d(x, y))
$$

where $G \in \triangle_{G}$ and $F$ satisfying $\left(F_{1}\right),\left(F_{2}\right)$ and $\left(F_{3}\right)$.

Theorem 10. ([12]) Let $(X, d)$ be a complete metric space. Let $T: X \rightarrow X$ be a self-mapping satisfying the following assertions:

(i) $T$ is an $\alpha$-admissible mapping with respect to $\eta$;

(ii) $T$ is an $\alpha-\eta$-GF-contraction;

(iii) there exists $x_{0} \in X$ such that $\alpha\left(x_{0}, T x_{0}\right) \geq \eta\left(x_{0}, T x_{0}\right)$;

(iv) $T$ is an $\alpha-\eta$-continuous.

Then $T$ has a fixed point. Moreover, $T$ has a unique fixed point when $\alpha(x, y) \geq \eta(x, x)$ for all $x, y \in$ Fix $(T)$.

Now we introduce the next new type of F-contractive mapping. Using it we proved the corresponding fixed point result:

Definition 10. Let $(X, d)$ be a metric space and $T$ be a self-mapping on $X$. The mapping $T$ is said to be a GF-contractive type mapping if for $x, y \in X$ with $d(T x, T y)>0$, holds

$$
G(d(x, T x), d(y, T y), d(x, T y), d(y, T x))+F(d(T x, T y)) \leq F(d(x, y)),
$$

where $G \in \triangle_{G}$ and $F$ satisfying $\left(F_{1}\right)$.

Theorem 11. Let $(X, d)$ be a complete metric space and let $T: X \rightarrow X$ be a continuous GF-contraction type mapping. Then $T$ has a unique fixed point and for all $x \in X$ the sequence $\left\{T^{n} x\right\}_{n \in \mathbb{N} \cup\{0\}}$ converges to this fixed point.

Proof. Firstly, let us consider the uniqueness of a possible fixed point. Assume the opposite, let $T$ has two distinct fixed points $x^{*}$ and $y^{*}$ from $X$. Then we have

$$
G\left(d\left(x^{*}, T x^{*}\right), d\left(y^{*}, T y^{*}\right), d\left(x^{*}, T y^{*}\right), d\left(y^{*}, T x^{*}\right)\right)+F\left(d\left(T x^{*}, T y^{*}\right)\right) \leq F\left(d\left(x^{*}, y^{*}\right)\right),
$$

that is,

$$
G\left(0,0, d\left(x^{*}, y^{*}\right), d\left(y^{*}, x^{*}\right)\right)+F\left(d\left(x^{*}, y^{*}\right)\right) \leq F\left(d\left(x^{*}, y^{*}\right)\right) .
$$

According to the property $(G)$ there exists $\tau>0$ such that $G\left(t_{1}, t_{2}, t_{3}, t_{4}\right)=\tau$. This further means that

$$
\tau+F\left(d\left(x^{*}, y^{*}\right)\right) \leq F\left(d\left(x^{*}, y^{*}\right)\right),
$$

which is a contradiction. Hence, the uniqueness of fixed point is proved if it exists.

In order to prove the existence of fixed point of $T$, let $x_{0} \in X$. We define the sequence $\left\{x_{n}\right\}$ by $x_{n+1}=T x_{n}, n \in \mathbb{N} \cup\{0\}$. If there exists $k \in \mathbb{N} \cup\{0\}$ such that $x_{k}=x_{k+1}$ then $x_{k}$ is unique fixed point and the proof is completed. Therefore, we assume that $x_{n} \neq x_{n+1}$, i.e. $d\left(T x_{n-1}, T x_{n}\right)>0$ for all $n \in \mathbb{N}$. Since $T$ is a GF-contractive type mapping we get 


$$
\begin{gathered}
G\left(d\left(x_{n-1}, T x_{n-1}\right), d\left(x_{n}, T x_{n}\right), d\left(x_{n-1}, T x_{n}\right), d\left(x_{n}, T x_{n-1}\right)\right) \\
+F\left(d\left(T x_{n-1}, T x_{n}\right)\right) \leq F\left(d\left(x_{n-1}, x_{n}\right)\right),
\end{gathered}
$$

which implies,

$$
\begin{gathered}
G\left(d\left(x_{n-1}, x_{n}\right), d\left(x_{n}, x_{n+1}\right), d\left(x_{n-1}, x_{n+1}\right), 0\right) \\
+F\left(d\left(x_{n}, x_{n+1}\right)\right) \leq F\left(d\left(x_{n-1}, x_{n}\right)\right) .
\end{gathered}
$$

Further, based on $(G)$ there is $\tau>0$ such that,

$$
G\left(d\left(x_{n-1}, x_{n}\right), d\left(x_{n}, x_{n+1}\right), d\left(x_{n-1}, x_{n+1}\right), 0\right)=\tau .
$$

Hence we deduce that,

$$
\tau+F\left(d\left(x_{n}, x_{n+1}\right)\right) \leq F\left(d\left(x_{n-1}, x_{n}\right)\right) .
$$

As in the proof of Theorem 4, it follows that $\lim _{n \rightarrow+\infty} d\left(x_{n}, x_{n+1}\right)=0$. Now, we will prove that $\left\{x_{n}\right\}_{n \in \mathbb{N} \cup\{0\}}$ is a Cauchy sequence by supposing the contrary holds. When we put $x=x_{n_{k}}$ and $y=x_{m_{k}}$ in the GF-contraction (it is possible by Lemma 2), we get

$$
\begin{gathered}
G\left(d\left(x_{n_{k}}, x_{n_{k}+1}\right), d\left(x_{m_{k}}, x_{m_{k}+1}\right), d\left(x_{n_{k}}, x_{m_{k}+1}\right), d\left(x_{m_{k}}, x_{n_{k}+1}\right)\right) \\
+F\left(d\left(x_{n_{k}+1}, x_{m_{k}+1}\right)\right) \leq F\left(d\left(x_{n_{k}}, x_{m_{k}}\right)\right) .
\end{gathered}
$$

By taking limit as $k \rightarrow+\infty$, from the last relation we obtain:

$$
G\left(0,0, \varepsilon^{+}, \varepsilon^{+}\right)+F\left(\varepsilon^{+}+0\right) \leq F\left(\varepsilon^{+}+0\right)
$$

and hence according to $(G)$, for some $\tau>0$, we get

$$
\tau+F\left(\varepsilon^{+}+0\right) \leq F\left(\varepsilon^{+}+0\right),
$$

which is a contradiction. Since, $(X, d)$ is a complete metric space the sequence $\left\{x_{n}\right\}_{n \in \mathbb{N} \cup\{0\}}$ converges to some point $\bar{x} \in X$. The continuity of $T$ and previous result show that the point $\bar{x}$ is a fixed point of $T$.

Combining Theorem 11 and Example 2 we obtain the genuine generalization of Wardowski's theorem without using the properties $\left(F_{2}\right)$ and $\left(F_{3}\right)$.

Recall that a self-mapping $T$ is said to have the property $(\mathcal{P})$ if $\operatorname{Fix}\left(T^{n}\right)=\operatorname{Fix}(T)$ for every $n \in \mathbb{N}$ (for more details see [13]). In [12] Hussain and Salimi proved the following result:

Theorem 12. ([12], Theorem 2.3) Let $(X, d)$ be a complete metric space and $T: X \rightarrow X$ be an $\alpha$-continuous self-mapping. Assume that there exists $\tau>0$ such that

$$
\tau+F\left(d\left(T x, T^{2} x\right)\right) \leq F(d(x, T x))
$$

holds for all $x \in X$ with $d\left(T x, T^{2} x\right)>0$ where $F$ satisfying $\left(F_{1}\right),\left(F_{2}\right)$ and $\left(F_{3}\right)$. If $T$ is an $\alpha$-admissible mapping and there exists $x_{0} \in X$ such that $\alpha\left(x_{0}, T x_{0}\right) \geq 1$, then $T$ has the property $(\mathcal{P})$.

Remark 2. It is worth mentioning that possible fixed point $x^{*}$ of $T$ does not satisfy the condition (28).

Our next result is, however, slightly more general than the previous one. 
Theorem 13. Let $(X, d)$ be a complete metric space and $T: X \rightarrow X$ be a self-mapping. Assume that there exists $\tau>0$ such that

$$
\tau+F\left(d\left(T x, T^{2} x\right)\right) \leq F(d(x, T x))
$$

holds for all $x \in X$ with $d\left(T x, T^{2} x\right)>0$ where $F:(0,+\infty) \rightarrow(-\infty,+\infty)$. If Fix $(T) \neq \varnothing$ then $T$ has the property $(\mathcal{P})$.

Proof. Assume contrarily, that $x^{*} \in \operatorname{Fix}\left(T^{n}\right)$ for some $n>1$ and $x^{*} \notin \operatorname{Fix}(T)$. Then, $d\left(x^{*}, T x^{*}\right)>0$. Let $n \in \mathbb{N}$ be a given. Since $x^{*} \in \operatorname{Fix}\left(T^{n}\right)$ we have $T^{n} x^{*}=x^{*}$. Further, we obtain

$$
\begin{gathered}
F\left(d\left(x^{*}, T x^{*}\right)\right)=F\left(d\left(T^{n} x^{*}, T^{n+1} x^{*}\right)\right)=F\left(d\left(T\left(T^{n-1} x^{*}\right), T^{2}\left(T^{n-1} x^{*}\right)\right)\right) \\
\leq F\left(d\left(T^{n-1} x^{*}, T\left(T^{n-1} x^{*}\right)\right)\right)-\tau=F\left(d\left(T^{n-1} x^{*}, T^{n} x^{*}\right)\right)-\tau \\
=F\left(d\left(T\left(T^{n-2} x^{*}\right), T^{2}\left(T^{n-2} x^{*}\right)\right)\right)-\tau \\
\leq F\left(d\left(T^{n-2} x^{*}, T\left(T^{n-2} x^{*}\right)\right)\right)-2 \tau \leq \ldots \leq F\left(d\left(x^{*}, T x^{*}\right)\right)-n \tau,
\end{gathered}
$$

which is a contradiction. Therefore, $\operatorname{Fix}\left(T^{n}\right)=\operatorname{Fix}(T)$ for all $n \in \mathbb{N}$.

We will now formulate the new type of contraction:

Definition 11. Let $(X, d)$ be a metric space. A mapping $T: X \rightarrow X$ is said to be a $(\varphi, F)$-weak contraction of Ćiric -type if there exists $F:(0,+\infty) \rightarrow(-\infty,+\infty)$ and $\varphi:(0,+\infty) \rightarrow(0,+\infty)$ satisfying $\left(F_{1}\right)$ and $\left(H_{2}\right)$ respectively, such that

$$
\varphi(d(x, y))+F(d(T x, T y)) \leq F(M(x, y))
$$

where

$$
M(x, y)=\max \{d(x, y), d(x, T x), d(y, T y), d(x, T y), d(y, T x)\}
$$

An open question arises from here:

Open Question. Does each $(\varphi, F)$-weak contraction of Ćirić-type defined on complete metric space $(X, d)$ have a unique fixed point if $T$ or $F$ is continuous? Prove or disprove this problem.

\section{Conclusions}

In this manuscript we have obtained more new results on Wardowski's F-contractions. To prove them, we used only the $\left(F_{1}\right)$ property, which is a significant improvement on many known results in the existing literature. At the end of it we raised an unresolved question as a motivation for further research in this subject.

Author Contributions: Conceptualization, J.V. and S.M.; methodology, J.V., S.M., M.P. and S.R.; formal analysis, M.P. and S.R.; investigation, J.V., S.M. and M.P.; data curation, M.P. and J.V.; supervision, M.P., S.R., J.V. and S.M.; project administration, J.V., M.P. and S.R. All authors have read and agreed to the published version of the manuscript.

Funding: This research received no external funding.

Conflicts of Interest: The authors declare no conflict of interest.

\section{References}

1. Banach, S. Sur les opérations dans les ensembles abstrait et leur application aux équations intégrales. Fund. Math. 1922, 3, 133-181. [CrossRef]

2. Mohammadi, B.; Parvaneh, V.; Aydi, H. On extended interpolative Ć irić-Reich-Rus type F-contractions and an application. J. Inequal. Appl. 2019, 2019, 290 [CrossRef] 
3. Lukacs, A.; Kajanto, S. Fixed point theorems for various types of $F$-contractions in complete $b$-metric spaces. Fixed Point Thepry 2018, 19, 321-334. [CrossRef]

4. Wardowski, D. Fixed points of a new type of contractive mappings in complete metric space. Fixed Point Theory Appl. 2012, 2012, 94. [CrossRef]

5. Abbas, M.; Nazir, T.; Rakočević, V. Common fixed points of family of multivalued F-contraction mappings on ordered metric spaces. Vietnam J. Math. 2020, 48, 11-21. [CrossRef]

6. Asif, A.; Nazam, M.; Arshad, M.; Kim, S.O. F-Metric, F-Contraction and Common Fixed-point Theorems with Applications. Mathematics 2019, 7, 586. [CrossRef]

7. Batra, R.; Vasishta, S. Fixed points of an F-contraction on metric spaces with a graph. Int. J. Comput. Math. 2014, 91, 2483-2490. [CrossRef]

8. Batra, R.; Vasishta, S. Fixed point theorem for $F_{\omega}$-contractions in complete metric spaces. J. Nonlin. Anal. Appl. 2013, 2013, 1-6.

9. Cosentino, M.; Vetro, P. Fixed point result for F-contractive mappings of Hardy-Rogers-Type. Filomat 2014, 28, 715-722. [CrossRef]

10. Dey, L.K.; Kumam, P.; Senapati, T. Fixed point results concerning $\alpha-F$-contraction mappings in metric spaces. Appl. Gen. Topol. 2019, 20, 81-95. [CrossRef]

11. Gubran, R.; Alfaqih, W.M.; Imdad, M. Fixed point theorems via WF-contractions. Krag. J. Math. 2021, 45, 353-360.

12. Hussain, N.; Salimi, P. Suzuki-Wardowski type fixed point theorems for $\alpha$-GF-contractions. Taiwan. J. Math 2014, 18, 1879-1895. [CrossRef]

13. Jeong, G.S.; Rhoades, B.E. maps for which $F(T)=F\left(T^{n}\right)$. Fixed Point Theory Appl. 2005, 18, 71-105.

14. Luambano, S.; Kumar, S.; Kakiko, G. Fixed point theorem for F-contraction mappings, in partial metric spaces. Lobacherskii J. Math. 2019, 40, 183-188. [CrossRef]

15. Minak, G.; Helvaci, A.; Altun, I. Ćirić type generalized F-contractions on complete metric spaces and fixed point results. Filomat 2014, 28, 1143-1151. [CrossRef]

16. Piri, H.; Kumam, P. Some fixed point theorems concerning F-contraction in complete metric spaces. Fixed Point Theory Appl. 2014, 2014, 210. [CrossRef]

17. Popescu, O.; Stan, G. Two fixed point theorems concerning F-contraction in complete metric spaces. Symmetry 2020, 12, 58. [CrossRef]

18. Secelean, N.A. Iterated function system consisting of F-contractions. Fixed Point Theory Appl. 2013, $2013,277$. [CrossRef]

19. Secelean, N.A. Weak F-contractions and some fixed point results. Bull. Iran. Math. Soc. 2016, 42, 779-798.

20. Shukla, S.; Radenović, S.; Kadelburg, Z. Some fixed point theorems for ordered F-generalized contractions in 0-f-orbitally complete partial metric spaces. Theory Appl. Math. Comput. Sci. 2014, 4, 87-98.

21. Turinci, M. Wardowski implicit contractions in metric spaces. arXiv 2013, arXiv:1211.3164.

22. Wardowski, D.; Van Dung, N. Fixed points of F-weak contractions on complete metric spaces. Demonstr. Math. 2014, 47, 146-155. [CrossRef]

23. Wardowski, D. Solving existence problems via F-contractions. Amer. Math. Soc. 2018, 146, 1585-1598. [CrossRef]

24. Radenović, S.; Kadelburg, Z.; Jandrlić, D.; Jandrlić, A. Some results on weakly contractive maps. Bull. Iran. Math. Soc. 2012, 38, 625-645.

25. Aleksić, S.; Mitrović, Z.D.; Radenović, S. Picard sequences in b-metric spaces. Fixed Point Theory 2020, 21, 35-46. [CrossRef]

26. Aydi, H.; Bota, M.F.; Karapinar, E.; Mitrović, S. A fixed point theorem for set-valued quasi-contractions in b-metric spaces. Fixed Point Theory Appl. 2012, 2012, 88. [CrossRef]

27. Mitrovic, Z.D. A note on the results of Suzuki, Miculescu and Mihail. J. Fixed Point Theory Appl. 2019, $21,24$. [CrossRef]

(C) 2020 by the authors. Licensee MDPI, Basel, Switzerland. This article is an open access article distributed under the terms and conditions of the Creative Commons Attribution (CC BY) license (http:/ / creativecommons.org/licenses/by/4.0/). 